\title{
Pesquisa avaliativa em reabilitação profissional: a efetividade de um serviço em desconstrução
}

\author{
Evaluative research on occupational rehabilitation: \\ the effectiveness of a health care service \\ subject to dismantlement
}

Mara Alice Batista Conti Takahashi 1

Ana Maria Canesqui 1

1 Departamento de Medicina Preventiva e Social. Faculdade de Ciências Médicas, Universidade Estadual de Campinas. C. P. 6111. Campinas, $S P$ 13084-971, Brasil.

\begin{abstract}
This article deals with the results obtained from 1995 to 1997 by an innovative occupational rehabilitation model for individuals with repetitive strain injury/work related musculoskeletal disorder (RSI/WRMD), developed by the Campinas Occupational Rehabilitation Center under the Brazilian National Institute for Social Security. The study had two objectives: 1) to reconstruct the program as a precondition for evaluation and 2) to evaluate the model's effectiveness in reestablishing the autonomy of individuals with RSI/WRMD. The methodology involved document analysis in order to reconstruct the program's background in terms of problem identification, organizational participation, awareness-raising, staff characteristics and responsibilities, and profile of the clientele. An analysis of 221 patient files provided the basis for constructing an evaluative instrument consisting of different dimensions, variables, and indicators, which was applied to a sample of 47 patient histories prior and subsequent to rehabilitative intervention. High effectiveness was observed in the model, with variations in the different target dimensions.
\end{abstract}

Key words Rehabilitation; Cumulative Trauma Disorders; Evaluation; Effectiveness

Resumo O texto aborda a avaliação dos resultados de um modelo assistencial inovado, no período de 1995 a 1997, para adoecidos por LER/DORT, desenvolvido no Centro de Reabilitação Profissional de Campinas do Instituto Nacional de Seguro Social. Dois objetivos foram postos pelo estudo: o de reconstituir o programa como precondição da avaliação e o de avaliar a efetividade do modelo assistencial adotado, quanto ao objetivo de resgatar a autonomia dos adoecidos. A metodologia envolveu o estudo e análise da documentação do programa para sua reconstituição quanto à identificação da problemática, inserção organizacional, as relações de interesse despertadas, a equipe e suas atribuições, e o perfil da clientela atendida. O estudo dos 221 prontuários dos atendidos no serviço permitiu a montagem de um instrumento avaliativo, composto de dimensões, variáveis e indicadores, que foi aplicado em uma amostra de 47 prontuários nos momentos antes e depois da intervenção. A elevada efetividade do modelo adotado foi constatada, comportando variações nas diferentes dimensões examinadas.

Palavras-chave Reabilitação; Transtornos Traumáticos Cumulativos; Avaliação; Efetividade 


\section{Introdução}

Os serviços de reabilitação profissional da Previdência Social foram questionados, na década de 90, quanto à eficácia de suas ações, à efetividade de seus resultados e à legitimidade de seus objetivos. O Relatório Final do Grupo de Trabalho Interministerial sobre Acidentes de Trabalho e Saúde do Trabalhador, apontou os Centros de Reabilitação Profissional (CRPs) do Instituto Nacional do Seguro Social (INSS) como executores de um "modelo ultrapassado, centralizado, inadequado e com desempenho não satisfatório" (MPAS, 1993:20) e propôs revisões, conceitual e prática, desses serviços que implicavam a sua descentralização, o fomento de parcerias com outras instituições e a padronização normativa dos programas para ampliar a cobertura.

Essa crítica fundamenta-se na ausência de uma política global da instituição previdenciária para com os acidentes de trabalho e as doenças profissionais, cujos dados oficiais demonstravam a ocorrência de 28.271 .828 casos notificados no período de 1970 a 1991, com 92.688 óbitos (Carmo et al., 1995). Os serviços de reabilitação foram apontados com uma atuação dissociada e omissa nas questões de prevenção e fiscalização das condições de trabalho, geradoras da magnitude desses eventos.

Após esse Relatório ficou demonstrado que não se tratava apenas de uma avaliação organizacional e dos métodos de trabalho da reabilitação profissional e sim, de uma crise política mais ampla, inserida na perspectiva da reforma previdenciária, na redefinição do papel do Estado, por meio do desmonte das políticas sociais, quer pela privatização de serviços (transferência de responsabilidades para outra instituição), quer pela focalização de clientela, isto é, elegendo seletivamente os grupos a ser atendidos.

Dentre as propostas de reforma do Estado, defendidas pelo governo de Fernando Henrique Cardoso, estava a previdenciária cujos argumentos de natureza fiscal e econômica justificavam o equilíbrio dos atuais e futuros déficits orçamentários do sistema e os efeitos sobre a política macroeconômica de estabilização. Essa reforma afetaria os direitos trabalhistas conquistados, mas ela não foi realizada integralmente graças às resistências suscitadas. O discurso dessa proposta assentava-se em argumentos de natureza exclusivamente econômica, integrando-os ao ideário de formação intencionada de uma cultura política de crise, fortemente marcada pelo pensamento privatista, reduzindo o direito aos benefícios sociais e estimulando o pagamento pelos planos de saúde e de aposentadoria, por meio de seguros privados, como mais uma estratégia econômica de reordenação capitalista (Mota, 1995).

Outros argumentos eram contrários àquela proposta, lembrando Andrade (2000:7), que o "desequilíbrio não é componente intrínseco de regimes de repartição públicos e equilíbrio não é um atributo exclusivo dos sistemas privados de capitalização", e propondo a alteração do financiamento, mediante a taxação sobre o faturamento e o lucro das empresas como bases efetivas de custeio mais amplo da Seguridade Social.

A Previdência Social, em 1995, fez uma proposta de privatização do Seguro do Acidente de Trabalho (SAT), cujas arrecadação e gerenciamento seriam feitos por entidades privadas de fins lucrativos ou não, que se responsabilizariam pela provisão de prestações e serviços previdenciários, dentre eles os de reabilitação profissional (Schubert, 1996). Essa proposta também não foi implementada devido à conformação das resistências.

Constatou-se que, ao contrário de um período de expansão e consolidação dos serviços de Reabilitação Profissional no Brasil, ocorrido nas décadas de 70 e 80 , na década de 90 , sob o signo do ajuste macroeconômico e da reordenação do papel do Estado, iriam ocorrer mudanças no nosso frágil sistema de proteção social que provocariam uma redefinição e encolhimento daqueles serviços.

Apesar desse contexto favorável ao desmonte, vigiram nos âmbitos institucionais internos de alguns CRPs experiências inovadoras voltadas para a mudança do modelo assistencial, que queriam romper com a lógica da concepção securitária brasileira focalizada exclusivamente na recuperação da capacidade laborativa da clientela, como uma preocupação com a reprodução e manutenção da força de trabalho, vinculada exclusivamente às determinações de ordem econômica (Soares, 1991). Os modelos assistenciais tradicionais de reabilitação profissional ancoravam-se apenas nas intervenções clínicas individualizadas, desprovidas de investimentos nos vínculos com os pacientes e ensurdecidas quanto às suas necessidades e anseios.

Este artigo resulta de uma pesquisa avaliativa realizada no Programa de Atenção aos Adoecidos de LER/DORT (Lesões por Esforços Repetitivos/Distúrbios Osteomusculares Relacionados ao Trabalho) do CRP-Campinas, que incorporou um modelo assistencial renovado, avaliado no período de 1995 a 1997, subproduto da Dissertação de Mestrado de Takahashi (2000). 
Embora esse programa tenha sido transitório, a avaliação ex-post da efetividade dos resultados alcançados pelo modelo de intervenção adotado, permitiu demonstrar a importância da experimentação de inovações que podem contribuir para a redefinição de modelos assistenciais voltados à reabilitação de trabalhadores adoecidos por LER/DORT, cujos registros sobre o tema são bastante escassos na literatura.

\section{Material e métodos}

O aporte metodológico desta pesquisa ancorase em Martinic (1997), que concebe o sentido da avaliação de programas sociais como a emissão de juízo de valor ou de um julgamento, feito por uma pessoa ou equipe, sobre as atividades e resultados de um programa de intervenção social. $\mathrm{O}$ avaliador recorre a um conjunto de critérios e a um marco referencial que lhe permite comparar, contrastar e interpretar os resultados observados em função de um ou vários padrões explícitos ou implícitos.

Dois objetivos básicos foram postos no estudo. O primeiro foi o de reconstituir o programa implementado pela equipe de LER do CRPCampinas. Segundo recomendação de Martinic (1997), para dar início à avaliação é necessário compreender tanto os elementos internos da intervenção, ou sejam, as relações estabelecidas entre os seus propósitos (explícitos ou implícitos), quanto os meios e resultados produzidos, juntamente com os elementos externos, isto é, os contextuais que também condicionam as possibilidades de êxitos ou fracassos da intervenção.

Essa etapa requereu a identificação e leitura exaustiva de 221 prontuários que representaram a totalidade dos casos atendidos pelo serviço no período de agosto de 1995 a dezembro de 1997, dos quais pôde-se extrair o perfil da clientela atendida e a identificação do modelo assistencial e de sua lógica e objetivos.

O segundo objetivo do estudo foi o de avaliar os resultados do modelo assistencial em relação ao seu propósito de resgatar a autonomia dos adoecidos por LER/DORT. O resgate da autonomia foi entendido no sentido de que os adoecidos estavam acometidos por um conjunto de limitações, que podia conduzi-los a graus diferenciados de agravamento da incapacidade associada à doença, sendo, entretanto, possível a eles desenvolver modalidades de convivência com as limitações decorrentes, produzindo portanto, "novas formas de andar a vida”, sempre com base em uma concepção vitalista da saúde, proposta por Canguilhem
(1995), que se contrapõe à concepção estanque e polar do normal e do patológico, tão cara ao modelo biomédico.

Dessa forma, da leitura das anotações dos profissionais feitas nos 221 prontuários que somaram os atendimentos no período pesquisado, pôde-se extrair os cômputos das freqüências absolutas das referências feitas por eles, que foram retraduzidas e interpretadas pelo avaliador nas dimensões, variáveis e indicadores do estudo. Eles estão expostos na Tabela $1 \mathrm{e}$ se constituíram em um instrumento metodológico importante na avaliação. Delas equacionou-se o estado de incapacidade dos adoecidos nas seguintes dimensões: (1) a física, que é preponderante, à medida em que o adoecimento provoca um conjunto de sintomas e sensações desagradáveis; (2) o uso social do corpo que permite superar a visão meramente mecânica e funcional posta pela reabilitação, substituindo-a pela capacidade dos adoecidos em usar adequadamente o seu corpo nas atividades cotidianas; (3) a dimensão do emocional, identificada por um conjunto de estados psicológicos e (4) a dimensão da sociabilidade, incluindo os aspectos relacionais em geral e os específicos ao trabalho.

Uma vez construído esse instrumento, ele foi aplicado na avaliação propriamente dita, feita mediante uma amostra de 47 prontuários, selecionada segundo os seguintes critérios: diagnósticos da LER/DORT grau III, cumprimento integral de todas as atividades do programa e encaminhamento exclusivo da Perícia Médica do INSS de Campinas. Observa-se que os casos diagnosticados no grau III são definidos segundo a Norma Técnica de Avaliação da Incapacidade por LER (MPAS, 1993:18) como: "A dor é mais persistente, é mais forte e tem irradiação mais definida(...) Há freqüentes paroxismos dolorosos(...) Há sensível queda de produtividade quando não impossibilidade de executar a função(...) Os sinais clínicos estão presentes: o edema é freqüente e recorrente, a hipertonia muscular é constante, as alterações de sensibilidade estão quase sempre presentes, especialmente nos paroxismos dolorosos e acompanhadas por manifestações vagas como palidez, hiperemia e sudorese da mão. A mobilização ou palpação do grupo muscular acometido provoca dor forte. Nos quadros com comprometimento neurológico compressivo, a eletroneuromiografia pode estar alterada. Nessa etapa o retorno à atividade produtiva é problemático. Prognóstico reservado".

Este estudo caracteriza-se como avaliação ex-post, isto é, feito após a intervenção. Incluiu a abordagem do programa nos momentos an- 
Tabela 1

Dimensões, variáveis e indicadores utilizados para avaliar o programa de LER/DORT

do Centro de Reabilitação Profissional. Campinas, São Paulo, Brasil.

\begin{tabular}{|c|c|c|}
\hline Dimensões & Variáveis & Indicadores \\
\hline \multirow[t]{9}{*}{ Dimensão física } & Presença da dor & Dor intensa e ininterrupta. \\
\hline & & Dor somente ao usar os membros superiores. \\
\hline & Limitações funcionais & Dificuldades para elevar ou sustentar os membros superiores. \\
\hline & & Dificuldades para mover mãos e punhos. \\
\hline & & Fadiga precoce e perda de força muscular. \\
\hline & & Presença de tensão muscular acentuada. \\
\hline & Sensações incômodas & Parestesias persistentes. \\
\hline & & Hipotermia e sudorese. \\
\hline & & Presença de edemas. \\
\hline Dimensão do uso social & Realização das tarefas cotidianas & Diminuição do ritmo ao realizar tarefas domésticas. \\
\hline do corpo & & Baixa tolerância à escrita. \\
\hline & & Dificuldades no autocuidado corporal. \\
\hline \multirow[t]{3}{*}{ Dimensão do emocional } & Aspectos psicológicos & Depressão severa. \\
\hline & & Quadro de ansiedade intensa. \\
\hline & & Crises de irritabilidade. \\
\hline \multirow[t]{4}{*}{ Dimensão da sociabilidade } & Aspectos dos relacionamentos & Relacionamento familiar conflituoso. \\
\hline & sociais e de trabalho & Aversão às chefias e colegas de trabalho. \\
\hline & & Incapacidade para o lazer. \\
\hline & & Impossibilidade de trabalhar. \\
\hline
\end{tabular}

LER/DORT = lesões por esforços repetidos/distúrbios osteomusculares relacionados ao trabalho.

tes e depois da intervenção que, segundo Martinic (1997), permite caracterizar as mudanças produzidas num tempo considerado, a ser verificadas, com base em algumas evidências. $\mathrm{O}$ interesse foi o de aferir o quanto o conjunto das dimensões, variáveis e indicadores foi alterado ou não em função da intervenção, uma vez consideradas as manifestações da incapacidade ou da falta de autonomia dos pacientes nos momentos antes (na primeira consulta) e depois (por ocasião da alta).

A avaliação da efetividade preocupa-se com os resultados ou o impacto e aplica-se a programas que querem efetuar mudanças, que podem ser objetivas, subjetivas ou substantivas (Figueiredo \& Figueiredo, 1986). Neste estudo, a avaliação de efetividade aferiu as mudanças, nos momentos antes e depois da intervenção, o que permitiu estabelecer a comparação entre os resultados sobre a condição de incapacidade dos adoecidos, obtidos num e noutro momento (Canesqui, 2002 ).

\section{Resultados}

\section{A reconstituição do modelo assistencial}

Se um dos objetivos do estudo foi o de reconstituir o modelo assistencial de LER/DORT do CRP-Campinas, como uma precondição da avaliação, a seguir passamos a caracterizá-lo, segundo os seguintes aspectos:

\section{a) Os antecedentes da problemática}

A LER/DORT era uma situação-problema no Município de Campinas, uma vez que os profissionais do CRP se deparavam com casos graves, sem o nexo-causal reconhecido, nem pelos médicos das empresas, nem pelos peritos do INSS. Os adoecidos afastavam-se sucessivamente do trabalho, a ele retornando nas mesmas condições que provocaram o adoecer, obtendo o agravamento de sua condição. A ausência de reconhecimento social da doença não mobili- 
zava nenhuma reação coletiva de mudança das suas condições geradoras. A reversão desse quadro impunha-se. Um número grande de adoecidos de LER/DORT precisava de atendimento terapêutico, que lhes resgatasse a autonomia funcional e o equilíbrio emocional como condições imprescindíveis para o retorno ao trabalho. Esse foi um dos objetivos do programa, com base no consenso da equipe.

\section{b) A lógica da intervenção}

A lógica da intervenção é um componente muito importante na reconstituição de um programa e permite apreender as escolhas adotadas pelos atores da intervenção na consecução dos objetivos pretendidos. Segundo Martinic (1997), ela é derivada das concepções e marcos de referência desses atores e vão sustentar as relações causais entre a situação-problema e os objetivos da intervenção.

A lógica da intervenção da equipe de LER estabeleceu rupturas com os modos de atuar tradicionais da Reabilitação Profissional do INSS e articulou reabilitação com prevenção, rompendo com o isolamento característico dos CRPs, estabelecendo parcerias interinstitucionais, garantindo um melhor equacionamento social da problemática no Município de Campinas, junto com o controle social dos adoecidos sobre as ações e intenções do projeto, por intermédio de sua associação e sindicatos.

O modelo terapêutico procurou romper com o modelo biomédico vigente na área, implementando um modo de atenção integral e integrado, ultrapassando a intervenção clínica individualizada e centrada nos aspectos físicos e da compatibilidade dos adoecidos ao trabalho, reconhecendo as limitações em outras dimensões, como a emocional, relacional e social, e desenvolvendo novos recursos adaptativos para o resgate da autonomia dos adoecidos, não só para o trabalho, mas para a vida em geral.

\section{c) As relações de interesse}

Todo projeto de intervenção provoca muitas reações pois, como observa Martinic (1997), afeta tanto as pessoas beneficiárias como outros interesses que podem dificultar ou facilitar a realização das ações previstas, atuando como um "jogo de forças" que pode anular os resultados de um projeto ou legitimar os seus objetivos. O projeto de LER/DORT do CRP-Campinas desencadeou simultaneamente atitudes positivas e negativas de diversos atores sociais.

Não havia contradição entre as disposições legais da reabilitação profissional do INSS e as ações do projeto, e as citadas rupturas ocorriam apenas como contradições à lógica dominante na instituição. As direções do INSS de Campinas (direção do CRP, supervisão da Perícia Médica e gerência regional) garantiram a alocação dos recursos humanos e materiais e ofereceram apoio institucional. Os assistidos mantiveram uma percepção positiva do programa, uma vez legitimado pelos sindicatos e pela associação dos adoecidos. Este também contou com o respaldo político das diversas instituições públicas e privadas que compunham o Grupo Interinstitucional de LER (GIL) do Município de Campinas.

As reações contrárias foram observadas nas atitudes das empresas que resistiam em reconhecer a LER/DORT como uma problemática decorrente das condições de trabalho, não acolhiam adequadamente os adoecidos reabilitados e descumpriam as condições acordadas nas negociações de retorno, o que levou o CRPCampinas a formalizar várias denúncias contra elas no Ministério Público Federal do Trabalho. As supervisões estadual e nacional da reabilitação profissional do INSS também foram fortemente contrárias à continuidade do projeto, e faziam pressão institucional e pessoal para seu enquadramento nos moldes dos atendimentos tradicionais, cuja inadequação na abordagem dos acidentados e adoecidos do trabalho já era demonstrada. Elas serviram de apoio às propostas de desmonte articuladas na esfera macroadministrativa e política da Previdência Social.

\section{d) O contexto institucional e a inserção organizacional}

O Programa de Atenção a LER/DORT foi levado a efeito por iniciativa de uma das cinco equipes de reabilitação profissional que atuavam no CRP-Campinas no período estudado. A equipe se reportava técnica e administrativamente a uma supervisão de atividades terapêuticas e à direção do CRP, e contou com o apoio institucional dessas duas instâncias, o que lhe garantiu, por determinado tempo, condições favoráveis para seu funcionamento; entretanto, não se pode minimizar os efeitos desestabilizadores da reforma em curso que afetaram profundamente sua continuidade.

As suas atividades adequavam-se aos objetivos e à "missão" institucional do serviço, ou seja, o de promover o retorno ao trabalho dos segurados da Previdência Social acidentados e adoecidos do trabalho, encaminhados pela Perícia Médica do INSS, cujo processo de reabilitação, além das atividades terapêuticas, envolvia a profissionalização e a negociação com as 
empresas para a recolocação dos reabilitados em funções compatíveis.

\section{e) Os aspectos internos do programa de LER/DORT}

O projeto terapêutico foi pensado como um trabalho interdisciplinar que envolvia, além dos atendimentos individuais ou em grupo, reuniões técnicas semanais para discussão de casos e definição de metodologias de intervenção.

Por intermédio de reuniões interinstitucionais foi formado o GIL para intervir nas empresas e provocar mudanças nas condições de trabalho que estavam gerando a doença. Coube principalmente aos assistentes sociais desenvolver essas atividades.

No âmbito interno do serviço, os resultados obtidos foram sistematizados nas práticas mais importantes de cada categoria profissional e seus objetivos específicos, envolvidos na intervenção.

$\mathrm{O}$ assistente social ainda fazia os levantamentos situacionais e profissionais junto aos adoecidos e, após sua análise, contextualizava os casos nas reuniões técnicas da equipe, fornecendo os elementos sociais necessários para subsidiar a definição das capacidades laborativas residuais e orientação das diversas áreas para os programas de reabilitação. Orientava os direitos trabalhistas e de cidadania, na busca de melhores alternativas de volta ao trabalho. Eram atividades concebidas como terapêuticas pois, conforme Souza (1997:160), "viabilizavam outros canais de liberação da energia mobilizada pelo sofrimento, em que pudessem encontrar uma linguagem para elaborar, de forma real, os sofrimentos de injustiça e impotência diante do problema".

O médico medicava e prescrevia tratamentos em situações de crises agudas, avaliando também clinicamente as condições globais de saúde de cada adoecido, o seu grau de comprometimento físico, os limites funcionais e a compatibilidade com a função exercida e a exercer por ocasião do retorno.

O psicólogo estimulava individualmente a elaboração dos sentimentos dos adoecidos, decorrentes da perda funcional e emocional vivenciada de modo singular, trabalhando na aceitação dos limites, na aprendizagem da convivência com a dor e no estabelecimento de novas condutas para a satisfação de seus anseios. $\mathrm{O}$ trabalho em grupo objetivava desenvolver os aspectos sadios dos adoecidos e por meio de um processo de identificação, tornava possível ressignificar a LER/DORT, segundo um referencial coletivo, reduzindo o nível de angústia e proporcionando o suporte emocional para a reconstrução da identidade abalada pela doença.

O fisioterapeuta oferecia atividades para que os adoecidos pudessem desenvolver a percepção do próprio corpo, conhecendo as suas estruturas e as suas inter-relações, visando garantir a autonomia na criação ou alterações dos hábitos posturais e funcionais comprometidos, diminuindo as sobrecargas físicas e tensionais.

O terapeuta ocupacional, servindo-se de técnicas específicas, possibilitava vivências para os adoecidos desenvolverem posturas corretas, mediante a observação e o autoconhecimento da inter-relação entre tempo, ritmo, respiração e tensão muscular na realização de tarefas e nos movimentos de segurar objetos; aprendendo, por meio de relaxamentos, novos caminhos funcionais adaptativos. Esse trabalho oferecia ainda adaptações dos adoecidos para as atividades da vida diária e do lazer. Segundo Melo (1998), utilizando-se de atividades lúdicas, expressivas e de relaxamento, realizadas num setting grupal, possibilitando que a troca entre seus participantes, do que foi experimentado, seja um potencializador para o autoconhecimento dos hábitos funcionais e posturais, o que poderá levar a uma efetiva modificação dos mesmos.

No período delimitado pelo estudo, atuaram na Equipe de LER/DORT três assistentes sociais, um sociólogo, dois médicos, três psicólogos, dois fisioterapeutas e dois terapeutas ocupacionais. As várias alterações na composição da equipe respondiam às necessidades de uma demanda sempre crescente de adoecidos que precisava ser equacionada com as lacunas provenientes do processo de desmonte do serviço, que, como já dissemos, vinha sendo implementado pela Previdência Social em âmbito nacional, por meio de pedidos de demissão incentivada e aposentadorias precoces, motivadas pela ameaça constante de perdas de direitos trabalhistas dos servidores públicos.

O programa de LER/DORT não necessitou de recursos adicionais, a não ser os tradicionalmente viabilizados para os programas: passagens e diárias, auxílio-alimentação, auxílio-documentação, mensalidades para cursos profissionalizantes e aquisição de instrumentos de trabalho para possibilitar o serviço autônomo, além dos salários da própria equipe. A capacidade instalada do serviço foi suficiente para a realização das atividades planejadas e os profissionais definiram autonomamente a sua própria capacidade de atendimento, a despeito das intensas pressões por agilização exercidas pelas supervisões estadual e nacional da área de reabilitação profissional do INSS. 


\section{f) O perfil da clientela}

Com base nos dados obtidos por meio da quantificação dos 221 prontuários foi possível identificar o perfil da clientela beneficiária do projeto. Os dados sistematizados no estudo de Takahashi (2000) apontaram uma clientela majoritariamente feminina, cobrindo $87 \%$ (193) do universo, sendo que $13 \%$ (28) era constituída de homens. Esse perfil de gênero assemelhava-se ao encontrado em outros serviços públicos de atendimento de LER/DORT (Sato et al., 1993), e refletia a questão de poder e desigualdade social entre os gêneros encontrada no mundo do trabalho. Para as mulheres, reservavam-se os trabalhos monótonos e repetitivos, desprovidos de conteúdo intelectual, que exigem movimentos leves, delicados e precisos, de atenção concentrada, grande responsabilidade e paciência, atividades muito próximas de seus papéis familiares, condizentes com o papel feminino, construído socialmente.

Isso explicaria os diferentes impactos que a exposição de riscos ocupacionais, determinados pelas condições e fatores da organização do trabalho, provocam de modo específico em homens e mulheres, contrariando teorias, tão caras às empresas, de um destino biológico e naturalizado, onde haveria uma predisposição feminina para o adoecimento por essa patologia.

Os adoecidos eram, em sua maioria, adultos jovens, sendo que $87 \%$ (193) tinham entre 20 e 44 anos. Esse resultado levou-nos a inferir que, por se tratar a LER/DORT de uma doença ocupacional ligada às exigências de produtividade exacerbadas, os indivíduos jovens, os que estão em sua fase de vida mais produtiva, são os mais atingidos porque são os mais requisitados pelos parâmetros capitalistas de contratação e exploração da força de trabalho.

Quanto ao significado desse adoecimento e incapacitação profissional em pessoas tão jovens, constatamos uma faceta ainda mais dolorosa: a destruição de projetos de vida - representando uma perda muito significativa da identidade pessoal e profissional. Para o indivíduo jovem, as transformações impostas pela doença provocam uma ruptura na antiga identidade já que essa deixou de ser reposta pelo meio social, portanto é preciso que ele busque novos referenciais para que se reconheça, reorganize sua história pregressa e construa um novo projeto de futuro (Lima et al., 1996).

Em relação à escolaridade, a LER/DORT veio modificar de modo importante o perfil da clientela previdenciária atendida nos CRPs, habitualmente composta por trabalhadores que exerciam funções menos qualificadas e traba- lhos braçais que não exigiam escolarização. No universo dos adoecidos de LER/DORT atendidos pelo CRP-Campinas no período, 43\% (95) declararam ter cursado o 1o grau, $30 \%$ (66) o 2 o e $22 \%$ (50) tinham o 3o grau ou nível universitário.

A distribuição dos adoecidos de LER/DORT pelos diferentes ramos de atividades produtivas leva ao entendimento da importância de sua ocorrência, segundo alguns ramos de atividades, sendo que o ramo bancário foi o mais representado entre os atendidos, com $35 \%$ (78), seguido pela indústria metalúrgica com $28 \%$ (63) e pelos serviços hospitalares com 11\% (24). Embora seja bastante controvertida a discussão sobre a causalidade da LER/DORT, as formas de organização dos processos de trabalho, seu ritmo e intensificação, os modelos gerenciais e as tecnologias adotadas se imbricam no desgaste físico e psíquico dos trabalhadores, sendo a LER/DORT uma dessas expressões.

\section{A avaliação propriamente dita}

Como segundo objetivo do estudo, apresentamos os resultados obtidos na avaliação da intervenção do modelo assistencial de LER do CRPCampinas em relação ao seu propósito de resgate da autonomia dos adoecidos. O estudo da amostra dos 47 prontuários selecionados permitiu a montagem da Tabela 2 , contendo os resultados do cômputo das freqüências absolutas dos indicadores relacionados antes e depois da intervenção.

Na organização desse quadro interessou-se menos pela análise dos resultados quantitativos obtidos pelas freqüências e mais pelo seu uso como recurso metodológico da avaliação. Seguindo a proposta metodológica de Martinic (1997), os indicadores podem traduzir-se em unidades de observação das variáveis e dimensões que lhes correspondem, às quais foram atribuídas uma ponderação, ou uma qualificação traduzida em valores numéricos e que representam ao mesmo tempo a sua importância, conforme critérios valorativos do próprio avaliador, decorrentes de julgamento das concepções (reconstruídas) do modelo assistencial empregado e dos conteúdos do trabalho da equipe, anteriormente caracterizados.

A metodologia de análise comparativa e de aferição dos momentos antes e depois incluiu a ponderação prévia das dimensões e variáveis, com base em critérios qualitativos do avaliador, sendo que correspondeu à dimensão física o maior peso (40) por ser preponderante na definição da incapacidade dos adoecidos, distribuído nas seguintes variáveis: presença da dor (20), limitações físicas (15) e sensações 
Tabela 2

Apresentação da ponderação prévia valorativa das dimensões e variáveis do adoecimento por LER/DORT

e da quantificação dos seus indicadores, nos momentos antes e depois da intervenção.

\begin{tabular}{|c|c|c|c|}
\hline \multirow[t]{2}{*}{ Dimensões/Variáveis/Indicadores } & \multirow[t]{2}{*}{ Ponderação } & \multicolumn{2}{|c|}{ Momentos da intervenção } \\
\hline & & $\begin{array}{l}\text { Antes } \\
\text { Freqüência simples }\end{array}$ & $\begin{array}{l}\text { Depois } \\
\text { Freqüência simples }\end{array}$ \\
\hline Física & 40 & & \\
\hline Presença da dor & 20 & & \\
\hline Dor intensa e ininterrupta & & 43 & 1 \\
\hline Dor somente ao usar os membros superiores & & 4 & 0 \\
\hline Limitações funcionais & 15 & & \\
\hline Dificuldades para elevar e ou sustentar os membros superiores & & 25 & 9 \\
\hline Dificuldades para movimentar mãos e punhos & & 20 & 7 \\
\hline Fadiga precoce e diminuição da força muscular & & 38 & 15 \\
\hline Tensão muscular acentuada & & 6 & 0 \\
\hline Sensações incômodas & 5 & & \\
\hline Parestesias persistentes & & 17 & 14 \\
\hline Hipotermia e sudorese & & 10 & 0 \\
\hline Presença de edemas & & 17 & 0 \\
\hline Uso Social do Corpo & 30 & & \\
\hline \multicolumn{4}{|l|}{ Realização das tarefas cotidianas } \\
\hline Diminuição do ritmo ao realizar tarefas domésticas & & 35 & 13 \\
\hline Baixa tolerância à escrita & & 21 & 17 \\
\hline Dificuldades no autocuidado corporal & & 10 & 0 \\
\hline Emocional & 15 & & \\
\hline Aspectos psicológicos & 15 & & \\
\hline Depressão severa & & 21 & 7 \\
\hline Quadro de ansiedade intensa & & 22 & 7 \\
\hline Crises de irritabilidade & & 11 & 6 \\
\hline Sociabilidade & 15 & & \\
\hline Aspectos dos relacionamentos sociais & 15 & & \\
\hline Relações familiares conflituosas & & 11 & 0 \\
\hline Aversão às chefias e colegas de trabalho & & 22 & 2 \\
\hline Incapacidade para o lazer & & 5 & 1 \\
\hline Impossibilidade de trabalhar & & 47 & 13 \\
\hline
\end{tabular}

LER/DORT = lesões por esforços repetidos/distúrbios osteomusculares relacionados ao trabalho.

incômodas (5). À dimensão do uso social do corpo foi atribuído peso (30) por ser determinada fundamentalmente pela otimização da dimensão anterior, tendo se expressado por uma variável única, a realização das tarefas cotidianas (30). A essas dimensões seguiram-se a emocional e a da sociabilidade, cada qual recebendo peso (15) por serem entendidas como repercussões dos comprometimentos causados pela LER/DORT nas dimensões anteriores e suas variáveis de expressão foram, respectivamente, os aspectos psicológicos (15) e os aspectos dos relacionamentos sociais e de trabalho (15).
A Tabela 3 foi elaborada como uma matriz de julgamento e demonstra os resultados obtidos utilizando-se a multiplicação dos valores da freqüência absoluta dos indicadores pelos valores da ponderação e, a seguir, o cálculo dos índices de variação percentual do momento depois (D) da intervenção em relação ao momento antes (A), cuja expressão numérica é $\Delta=$ (1 - D/A) x 100, representando o resultado da intervenção, isto é, os percentuais obtidos, que traduzem as variações na obtenção do resgate da autonomia dos adoecidos.

Pode-se observar na Tabela 3 , que na dimensão física, fortemente marcada pela pre- 
sença intensa e ininterrupta da dor e por queixas de severa incapacitação, foi obtido um ganho de $63 \%$, não significando, contudo, a cura ou a volta à condição anterior ao adoecimento, já que esse não era o propósito definido pela equipe de atendimento. O resgate da autonomia significava a aquisição de novos padrões funcionais readaptativos que possibilitassem o convívio com a doença, lidando melhor com ela, conhecendo e respeitando seus limites e com isso obtendo o alívio e a supressão das crises agudas de dor.

A dimensão do uso social do corpo, cuja expressão de gênero se diferenciava, representava para as mulheres a impossibilidade de realizar, sem ajuda, as tarefas básicas como cozinhar, cuidar dos filhos pequenos, da roupa da família, da limpeza da casa e de si própria; e para os homens, de não poder carregar peso, de cuidar dos consertos da casa, de fazer barba e outras atividades. O resgate de autonomia foi de $55 \%$, com a diminuição dessas incapacidades que colocavam os adoecidos em uma situação de muito sofrimento existencial. Na dimensão emocional obteve-se a positividade de $65 \%$, pois os ganhos obtidos nas duas dimensões anteriores possi- bilitaram aos adoecidos readquirir o equilíbrio emocional e o resgate da auto-estima muito abalados pelo adoecimento.

Na dimensão da sociabilidade o ganho de $81 \%$ foi o maior de todas as dimensões, provocando alterações no sentimento de inutilidade que comprometia os adoecidos em seus conteúdos interpessoais e de volta ao trabalho. Finalmente os resultados totais demonstram que o programa provocou um ganho positivo de $64 \%$.

Para se avaliar, entretanto, o grau de efetividade da intervenção sobre o conjunto das manifestações da incapacidade, que comprometeu a autonomia dos adoecidos em "andar a vida”, um dos propósitos explícitos do programa, foi necessário montar uma escala que permite emitir o julgamento do avaliador, uma vez que a avaliação sempre implica a emissão de juízos de valor, conforme orientou-se conceitualmente neste estudo.

Assim, postos os graus de efetividade numa escala que varia de 0 a 100 pontos temos o seguinte: 0-19 pontos: efetividade muito baixa; 20-39 pontos: baixa; 40-59: média; 60-79: efetividade alta; 80-100: efetividade muito alta.

Resultados ponderados da variação das dimensões e variáveis, e sua comparação nos momentos antes e depois da intervenção.

\begin{tabular}{|c|c|c|c|c|c|c|}
\hline \multirow[t]{3}{*}{ Dimensões/variáveis } & \multirow[t]{3}{*}{ Valor de ponderação } & \multicolumn{4}{|c|}{ Momentos da intervenção } & \multirow[t]{3}{*}{$\Delta=(1-D / A) \times 100$} \\
\hline & & \multicolumn{2}{|c|}{ Antes } & \multicolumn{2}{|c|}{ Depois } & \\
\hline & & $\mathrm{F}$ & $F \times P$ & $\mathrm{~F}$ & $F \times P$ & \\
\hline Física & 40 & & & & & \\
\hline Presença da dor & 20 & 47 & 940 & 19 & 380 & \\
\hline Limitações funcionais & 15 & 89 & 1.335 & 31 & 465 & \\
\hline Sensações incômodas & 5 & 44 & 220 & 14 & 70 & \\
\hline Subtotal & & 180 & 2.495 & 64 & 915 & $63 \%$ \\
\hline Uso social do corpo & 30 & & & & & \\
\hline $\begin{array}{l}\text { Dificuldade na realização } \\
\text { das tarefas cotidianas }\end{array}$ & 30 & 66 & 1.980 & 30 & 900 & \\
\hline Subtotal & & 66 & 1.980 & 30 & 900 & $55 \%$ \\
\hline Emocional & 15 & & & & & \\
\hline Aspectos psicológicos & 15 & 54 & 810 & 20 & 300 & \\
\hline Subtotal & & 54 & 810 & 20 & 300 & $65 \%$ \\
\hline Sociabilidade & 15 & & & & & \\
\hline $\begin{array}{l}\text { Relacionamentos sociais } \\
\text { e de trabalho }\end{array}$ & 15 & 85 & 1.260 & 16 & 240 & \\
\hline Subtotal & & 85 & 1.260 & 16 & 240 & $81 \%$ \\
\hline Total & 100 & 385 & 6.545 & 147 & 2355 & $64 \%$ \\
\hline
\end{tabular}

$F=$ freqüência simples; $F \times P=$ produto das freqüências $\times$ ponderação; $A=$ antes da intervenção; $D=$ depois da intervenção. 
Aplicando-se esses critérios de julgamento no índice global obtido pela avaliação, demonstrado na Tabela 3, concluímos que a intervenção atingiu um grau de efetividade alta ao atingir $64 \%$ no resgate da autonomia, uma vez que ela provocou mudanças significativas nos acometimentos dos adoecidos. Graus de efetividades distintos podem ser atribuídos às várias dimensões sendo muito alta em relação à sociabilidade; altas para a emocional e física e média para a dimensão do uso social do corpo.

De qualquer modo, houve a permanência de 36\% do efeito inalterado da intervenção empregada, o que pode associar-se tanto ao grau de limitação proporcionada pelo quadro de gravidade do próprio adoecimento (Grau III), quanto à permanência de certos obstáculos institucionais, como a rotatividade constante dos profissionais da equipe devido às ameaças aos servidores públicos feitas pelo governo federal, que ocasionou a corrida às aposentadorias precoces e pedidos de demissão incentivada, bem como a falta de apoio institucional das chefias estadual e nacional da área de Reabilitação Profissional do INSS que, desde o início, se posicionaram contrárias a esse modelo de atenção e exerciam pressão por agilização e enquadramento em sua condução.

\section{Conclusão}

Os efeitos positivos percebidos levaram-nos a concluir que o Modelo Assistencial de LER/ DORT do CRP-Campinas foi capaz de aliviar o sofrimento de muitas pessoas, resgatando-lhes a capacitação funcional, emocional e social e num nível mais amplo, contribuiu para o reconhecimento social dessa problemática no $\mathrm{Mu}$ nicípio de Campinas. Dessa forma, o modelo foi adequado e inovado para resgatar a autonomia dos adoecidos de LER/DORT, apesar de sua não-continuidade, devido à interferência dos elementos contextuais institucionais, no momento de desmonte dos CRPs.

Embora não tenhamos verificado as opiniões e comportamentos dos profissionais ligados ao programa, é provável que a sua forte adesão a ele, como também o processo de trabalho adotado (integrado e multidisciplinar), como foi caracterizado por meio de suas atribuições, tenham contribuído positivamente para garantir o elevado grau de efetividade do modelo. Certamente outras dimensões da intervenção poderiam ser avaliadas, juntamente com as tecnologias empregadas, mas não se constituíram em objeto desta pesquisa. Entretanto, este estudo, que se preocupou em dimensionar a efetividade, sob o ponto de vista qualitativo, procurou requalificar valorativamente o quantitativo, trazendo como resultado um exercício metodológico de avaliação, inspirado na proposta de Martinic (1997), que reitera a importância da condução da avaliação como elemento de aprendizagem para as equipes e de verificação dos resultados. 


\section{Referências}

ANDRADE, E. G., 2000. (Des)Equilíbrio da previdência social brasileira 1945-1997 (componentes econômico, demográfico e institucional). In: VI Congresso Brasileiro de Saúde Coletiva, Anais, CDROM, Salvador: ABRASCO.

CANESQUI, A. M., 2002. Avaliação de políticas e programas sociais: Conceitos e tipos de pesquisa. Cadernos de Serviço Social, 9:89-107.

CANGUILHEM, G., 1995. O Normal e o Patológico. Rio de Janeiro: Editora Forense Universitária.

CARMO, J. C.; ALMEIDA, I. M.; BINDER, M. C. P. \& SETTIMI, M. M., 1995. Acidentes de trabalho. In: Patologia do Trabalho (R. Mendes, org.), pp. 431455, Rio de Janeiro: Editora Atheneu.

FIGUEIREDO, M. F. \& FIGUEIREDO, A M. C., 1986. Avaliação política e avaliação de políticas: Um quadro de referência teórica. Análise e Conjuntura, 1:107-127.

LIMA, M. E. A.; ARAÚJO, J. N. C. \& LIMA, F. P. A., 1996. LER - Dimensões Ergonômicas e Psicossociais. Belo Horizonte: Editora Health.

MARTINIC, S. , 1997. Evaluación de Proyectos. México, DF: Editorial Comexani-Cejuv.

MELO, M. S., 1998. O Atendimento da Terapia Ocupacional aos Portadores de Lesão por Esforços Repetitivos. Monografia, São Paulo: Faculdade de Medicina, Universidade de São Paulo.

MPAS (Ministério da Previdência Social), 1993. Relatório Final do Grupo de Trabalho Interministerial sobre Acidentes de Trabalho. Portaria no 18. Brasília: MPAS.
MOTA, A. E., 1995. Cultura da Crise e Seguridade Social - Um Estudo sobre as Tendências da Previdência e da Assistência Social Brasileira nos Anos 80 e 90. São Paulo: Cortez Editora.

SATO, L.; ARAÚJO, M. D.; UDIHARA, M. A.; FRANCO, M. A. J.; NICOTERA, F. N.; DALDON, M. T. B.; SETTIMI, M. M. \& SILVESTRE, M. P., 1993. Atividade em grupo com portadores de LER: Aspectos psicossociais. Revista Brasileira de Saúde Ocupacional, 79:49-62.

SOARES, L. B. T., 1991. Terapia Ocupacional: Lógica do Capital ou Lógica do Trabalho? Saúde em Debate 42. São Paulo: Editora Hucitec.

SOUZA, M. C., 1997. As lesões por esforços repetitivos a experiência do Centro de Reabilitação Profissional - CRP/INSS-Campinas. In: Congresso Brasileiro de Saúde Coletiva, Livro de Resumos, p. 160, Águas de Lindóia: ABRASCO.

TAKAHASHI, M. A. B. C., 2000. Avaliação em Reabilitação Profissional. A Experiência de Adoecer por LER e o Resgate da Autonomia: Uma Trajetória Singular. Dissertação de Mestrado, Campinas: Faculdade de Ciências Médicas, Universidade Estadual de Campinas.

Recebido em 27 de agosto de 2002

Versão final reapresentada em 10 de março de 2003

Aprovado em 13 de junho de 2003 